Research Article

\title{
Loading-Rate Dependence of Rocks in Postfailure Region under Triaxial Compression
}

\author{
Yang Tang $\mathbb{D},{ }^{1}$ Seisuke Okubo, ${ }^{1}$ Jiang Xu, ${ }^{1}$ Hailong Zhang $\mathbb{D},{ }^{2}$ and Shoujian Peng $\mathbb{D}^{1}$ \\ ${ }^{1}$ State Key Laboratory of Coal Mine Disaster Dynamics and Control, Chongqing University, Chongqing 400044, China \\ ${ }^{2}$ School of Civil Engineering and Architecture, Chongqing University of Arts and Sciences, Chongqing 402160, China
}

Correspondence should be addressed to Hailong Zhang; hlzhang28@163.com

Received 7 July 2018; Accepted 16 September 2018; Published 11 October 2018

Academic Editor: Carlos Garcia-Mateo

Copyright (c) 2018 Yang Tang et al. This is an open access article distributed under the Creative Commons Attribution License, which permits unrestricted use, distribution, and reproduction in any medium, provided the original work is properly cited.

To study the loading-rate dependence of four types of rocks in the peak and postfailure regions, the alternative strain rate test method is employed in conducting triaxial compressive tests under different confining pressure and moisture conditions. An index of the loading-rate dependence in the postfailure region is proposed, and the effects of confining pressure and moisture condition on the index are analyzed. The reliability of the test results is verified by comparing the experimental and calculated results of stress relaxation. Following are the results. (1) The peak strength and postfailure behavior significantly depend on the loading rate. The indices $\left(n_{\mathrm{c}}\right.$ and $n_{\mathrm{d}}$ ) of the loading-rate dependence in the postfailure region obtained based on the elastic and unloading moduli show a good linear relationship. It is feasible to use $n_{\mathrm{c}}$ to evaluate the loading-rate dependence of rocks in the postfailure region. (2) The loading-rate dependence of the rock strength increases with the increase in the confining pressure. The effect of confining pressure on the loading-rate dependence in the postfailure region is related to the moisture condition state. (3) Water-saturation treatment will increase the loading-rate dependence in the peak and postfailure regions, and the effect of water is greater than that of the confining pressure. (4) The experimental and calculated results of stress relaxation in the postfailure region are in good agreement, thus validating the experimental results.

\section{Introduction}

An understanding of the time-dependent behavior of rocks is essential for the assessment of long-term deformation and stability of underground structures in mining engineering [1]. Loading-rate dependency of strength is one important aspect of the time-dependent behavior of rocks. The relationship between uniaxial compression strength and loading rate has been thoroughly studied [2]. In contrast, studies on the time dependency of rocks under the confining pressure are lacking [3]. In practical projects, the formation of postfailure regions around underground structures is unavoidable [4]. Many rock mechanics problems in engineering, such as stability of underground roadways and pillars, are closely related to the mechanical properties and loading-rate dependence of rocks in the postfailure region. Therefore, studying the loading-rate dependence of rocks in this region has practical significance.
Only a few papers have been published concerning the loading-rate dependence of rocks in the postfailure region compared to the peak-failure region. Rummel and Fairhurst [5] investigated the postfailure behavior of brittle rocks under uniaxial and biaxial compression. The average slope in the postfailure region was found to decrease with the increase in the strain rate, indicating that the deterioration in the load-carrying ability of brittle rocks at high strain rates is less than that at lower strain rates under uniaxial compression. Bieniawski [6] conducted compressive tests at a constant strain rate, changing strain rates, and constant loading conditions in the postfailure region. The results show that the slopes of the stress-strain curves in the postfailure region become increasingly horizontal with the decrease in the strain rate. This phenomenon helps improvise the stability of the rocks after failure. Peng and Podnieks [7] demonstrated that the stress-strain curves obtained at higher strain rates exhibited a lower negative 
slope, whereas those obtained at lower strain rates exhibited a higher negative slope. Later, Peng [8] conducted stress relaxation tests in the postfailure region to investigate the time-dependence behavior of rocks. Hashiba et al. [9] investigated the loading-rate dependence of a stress-strain curve in the postfailure region using the alternative strain rate (ASR) test method. However, the results are only qualitative, and there is no quantitative method for studying the loading-rate dependence of rocks in the postfailure region under confined and wet conditions.

Previous studies have shown that the peak strength is proportional to the $1 /(n+1)^{\text {th }}$ power of the loading rate, and the creep life is inversely proportional to the $n^{\text {th }}$ power of the creep stress level [10], where $n$ is the index of time dependence, and is closely related to the crack growth rate [11]. The lower the value of $n$, the greater is the time dependence [3]. The index $n$ can not only be used to evaluate the loadingrate dependence of the peak strength [12] and stress-level dependence of the creep life [13] but can also be used as a parameter in the numerical simulation of constitutive equations wherein the time dependence is considered [14]. Moreover, it can be applied to rock mass rating [15]. Hashiba and Fukui [3] reviewed the results of previous studies on the index $n$ of the peak strength under various loading conditions. However, relatively few studies have been conducted on the peak strength under confined and wet conditions. Furthermore, an index of the loading-rate dependence of rocks in the postfailure region has not been proposed. In fact, there are no clear conclusions concerning the relationship between the loading-rate dependence (in the postfailure region), confining pressure, and moisture condition, which is essential for assessing the stability of underground structures.

In this study, a series of triaxial compressive tests on four types of rocks are conducted under different confining pressure and moisture conditions (air-dried and wet). The new test method (ASR method) proposed by Hashiba et al. [9] is employed to conduct the tests. Moreover, an index for evaluating the loading-rate dependence of the rocks in the postfailure region and its calculation method are developed, for which cyclic loading-unloading tests are conducted. The effects of the confining pressure and moisture condition on the index in the postfailure region are investigated, and the results are compared with those in the peak-failure region. Finally, the results of the ASR tests are validated by conducting stress relaxation tests in the postfailure region and from the calculation of a nonlinear constitutive equation.

\section{Materials and Methods}

2.1. Specimen Description. Following are the four types of rocks employed for testing: Tage tuff, Ogino tuff, Emochi andesite, and Jingkou sandstone. Tage tuff was obtained from Tochigi Prefecture, Japan. It mainly contains Albite, Feldspar, and small amounts of calcite. Ogino tuff was obtained from Fukushima Prefecture, Japan. The main components are zeolite, mullite, and clay, with small amounts of plagioclase and biotite. Emochi andesite was obtained from Fukushima Prefecture, Japan. It mainly comprises plagioclase, pyroxene, and a small amount of biotite. Jingkou sandstone was obtained from Chongqing, China. The main components are quartz, feldspar, vermiculite, and muscovite. Table 1 lists the basic physical and mechanical parameters of the rocks. The saturated water contents of Tage tuff and Ogino tuff are greater than those of Emochi andesite and Jingkou sandstone, whereas the peak strengths are lower.

The specimens were obtained by drilling a block of rock and were then cut into cylindrical shapes with a diameter of $25 \mathrm{~mm}$ and a height of $50 \mathrm{~mm}$. The specimen surfaces were polished to ensure the flatness, verticality, and parallelism standards as per ISRM. The specimens of the four rocks were air-dried at room temperature for two weeks. For testing under wet conditions, the specimens were water-saturated using a vacuum pump. More than three specimens of each type of rock were employed for each testing condition.

Figure 1 shows the testing apparatus used for the tests. The maximum axial loading capacity was $500 \mathrm{kN}$, and the maximum axial displacement was $10 \mathrm{~mm}$. The load was measured using a load cell, and the displacement was measured using a linear variable differential transformer (LVDT).

2.2. Test Method. The ASR test method, which was introduced by Hashiba et al. [9], was used to conduct the tests. In this section, a brief introduction about the method is given. Figure 2 shows the stress-strain curve for the ASR test. The strain rate is switched between high $\left(C_{2}\right)$ and low values $\left(C_{1}\right)$ at uniform strain intervals $(\triangle \mathcal{E})$. Based on the experimental curve, indicated using thick lines in Figure 2, the stress increases abruptly with the increase in the strain rate at the location marked with $\bullet$, whereas it decreases at the location marked with $\bigcirc$. Therefore, the stress-strain curves for $C_{1}$ and $C_{2}$ can be obtained by connecting the points $\bullet$ and $\bigcirc$ using a spline function, respectively, indicated using thin lines in Figure 2.

In this study, the confining pressures were set to $0,3,6$, and $9 \mathrm{MPa}$ for the ASR tests. Based on previous suggestions [9], the strain rate was switched between $10^{-4} / \mathrm{s}\left(C_{2}\right)$ and $10^{-5} / \mathrm{s}\left(C_{1}\right)$, while the strain interval $(\triangle \mathcal{E})$ is set to $5 \times 10^{-4}$ under uniaxial compression and $8 \times 10^{-4}$ under triaxial compression. The peak strengths $\sigma_{2 \mathrm{f}}$ and $\sigma_{1 \mathrm{f}}$ corresponding to strain rates of $C_{2}$ and $C_{1}$, respectively, can be obtained using this method. Hence, the loading-rate dependence index $n$ of the peak strength can be calculated as follows:

$$
\frac{\sigma_{2 \mathrm{f}}}{\sigma_{1 \mathrm{f}}}=\left(\frac{C_{2}}{C_{1}}\right)^{1 /(n+1)} \text {. }
$$

The confining pressures in the cyclic loading-unloading tests were set to 3,6 , and $9 \mathrm{MPa}$. The strain rate was $10^{-4} / \mathrm{s}$.

\section{Results}

3.1. Alternative Strain Rate Test Results. Figure 3 shows the typical ASR test results of the air-dried rocks under different confining pressures. The existence of the confining pressure can effectively improve the bearing deformation capacity of 
TABle 1: Physicomechanical properties of the specimens.

\begin{tabular}{lccccc}
\hline Rock & $\begin{array}{c}\text { Density } \\
\left(\mathrm{g} / \mathrm{cm}^{3}\right)\end{array}$ & $\begin{array}{c}\text { Saturated } \\
\text { water content }\end{array}$ & $\begin{array}{c}\text { UCS } \\
(\mathrm{MPa})\end{array}$ & $\begin{array}{c}E \\
(\mathrm{GPa})\end{array}$ & $v$ \\
\hline Tage tuff & 1.74 & $15.04 \%$ & 22.26 & 3.83 & 0.32 \\
Ogino tuff & 1.81 & $10.53 \%$ & 27.35 & 4.02 & 0.31 \\
Emochi andesite & 2.11 & $6.98 \%$ & 77.50 & 10.05 & 0.25 \\
Jingkou sandstone & 2.29 & $4.81 \%$ & 67.49 & 11.89 & 0.24 \\
\hline
\end{tabular}

UCS: uniaxial compression strength, $E$ : Young's modulus, $v$ : Poisson's ratio.

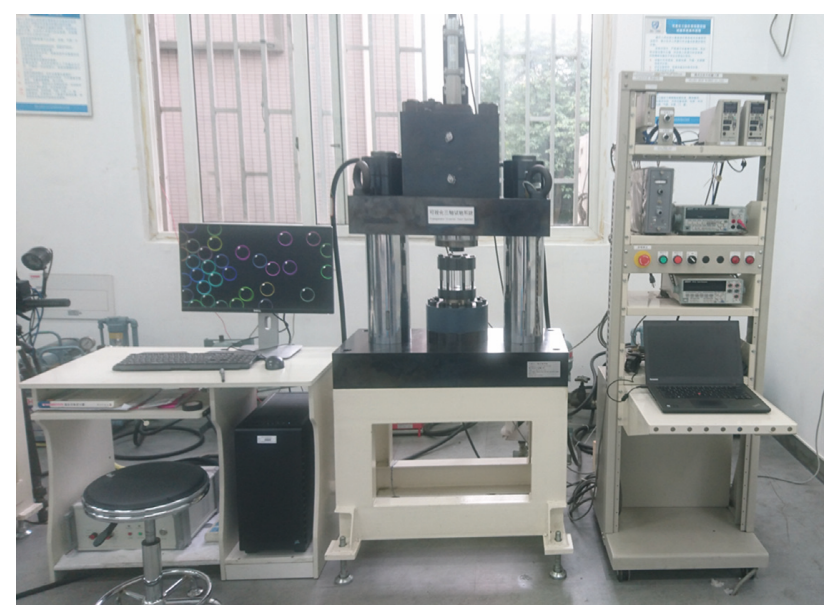

FIGURE 1: Servocontrolled test system for triaxial compression test.

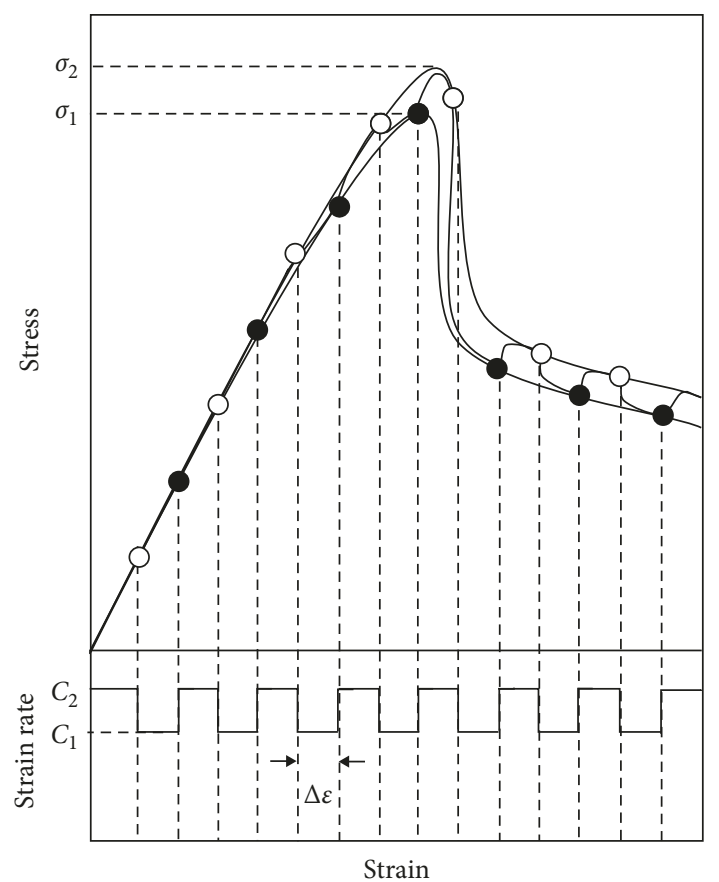

FIGURE 2: Schematic graph of alternative loading rate test [9].

the rocks in the postfailure region. When no confining pressure is applied, the stress decreases rapidly to a very low level after the peak strength point, and it is very difficult to quantitatively describe the loading-rate dependence in this stage. Nevertheless, the method described by Hashiba et al. [9] is found to be more effective. Hence, the index of the loading-rate dependence in the postfailure region was not calculated when the confining pressure was $0 \mathrm{MPa}$.

The stress-strain curves for the air-dried Tage tuff and Ogino tuff samples (Figures 3(a) and 3(b)) are similar. With the increase in the confining pressure, the peak strength gradually increases. After the peak strength, the stress-strain curves gradually transition from strain softening to approximately plastic behavior. Although no fluctuation in the stress is observed with respect to the change in the strain rate from the start of the test, the stress varies with the change in the strain rate as the stress increases up to the peak strength. The magnitude of the fluctuation is maximum near the peak strength point and gradually decreases thereafter. The stress in the postfailure region fluctuates with the change in the strain rate.

The stress-strain curves for the air-dried Emochi andesite and Jingkou sandstone samples (Figures 3(c) and 3(d)) are also similar. Compared to the curves for the Tage tuff and Ogino tuff samples, the difference is that the stress decreases abruptly after the peak strength and thereafter stabilizes in the postfailure region. In addition, the stress fluctuates with the change in the strain rate in the peak and postfailure regions.

The stress-strain curves for the four rock samples, shown in Figure 4, under the wet condition are similar to those under the air-dried condition. This stress fluctuation is closely related to the loading-rate dependence in the peak and postfailure regions. From the fluctuation, the index of the loadingrate dependence can be obtained using data analysis.

3.2. Cycle Loading-Unloading Test Results. The cyclic loading-unloading test was conducted to obtain the unloading modulus $\left(E_{\mathrm{d}}\right)$ in the postfailure region. This modulus will be used to calculate the index in the postfailure region. Therefore, the analyses of the mechanical properties of the rocks under the cyclic loading-unloading condition were excluded from the study.

Considering the results of Tage tuff under a confining pressure of $3 \mathrm{MPa}$ as an example, the method of calculating $E_{\mathrm{d}}$ is introduced as follows: Figure 5(a) shows the typical stressstrain curve obtained for the Tage tuff. In the cyclic loadingunloading test, hysteresis loops are generated, and $E_{\mathrm{d}}$ is obtained from the hysteresis loop, as shown in Figure 5(b).

The points $\mathrm{A}$ and $\mathrm{B}$ are the inflection points for unloading and reloading, respectively, and the slope of the line $A B$ is defined as the unloading modulus $E_{\mathrm{d}}$. For the airdried and wet Tage tuff and Ogino tuff samples, the change in the stress-strain curves in the postfailure region is gradual. Therefore, the average slope of all the lines $\mathrm{AB}$ after the peak strength is calculated as $E_{\mathrm{d}}$. For the air-dried and wet Emochi andesite and Jingkou sandstone samples, the average slope of the line $\mathrm{AB}$ is calculated as $E_{\mathrm{d}}$ when the stress-strain curves become horizontal after the decrease in the stress in the postfailure region. Table 2 lists the statistical results of $E_{\mathrm{d}}$ for the four air-dried and wet rock samples.

3.3. Index Calculation Method and Results. In this study, the index of the loading-rate dependence is denoted as $n$ for the peak-failure region and $n_{i}$ for the postfailure region. The 


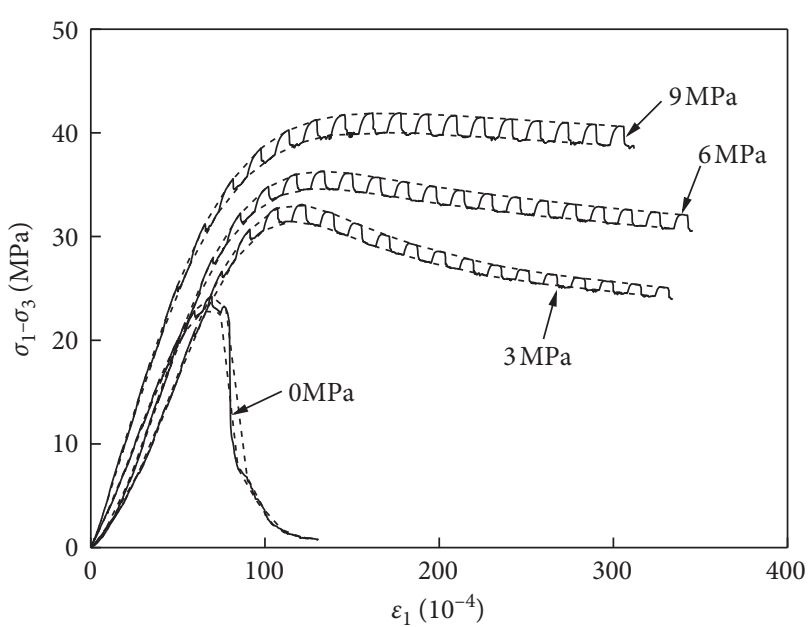

(a)

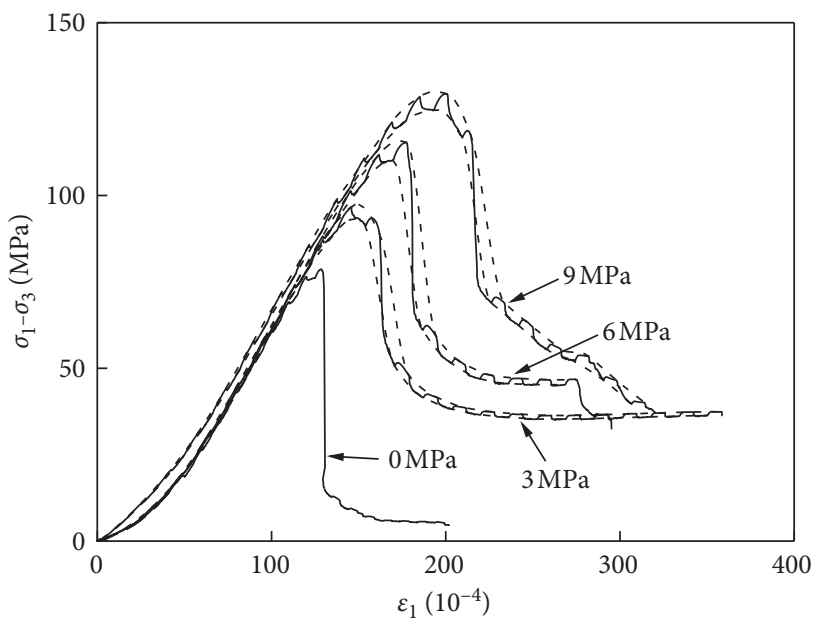

(c)

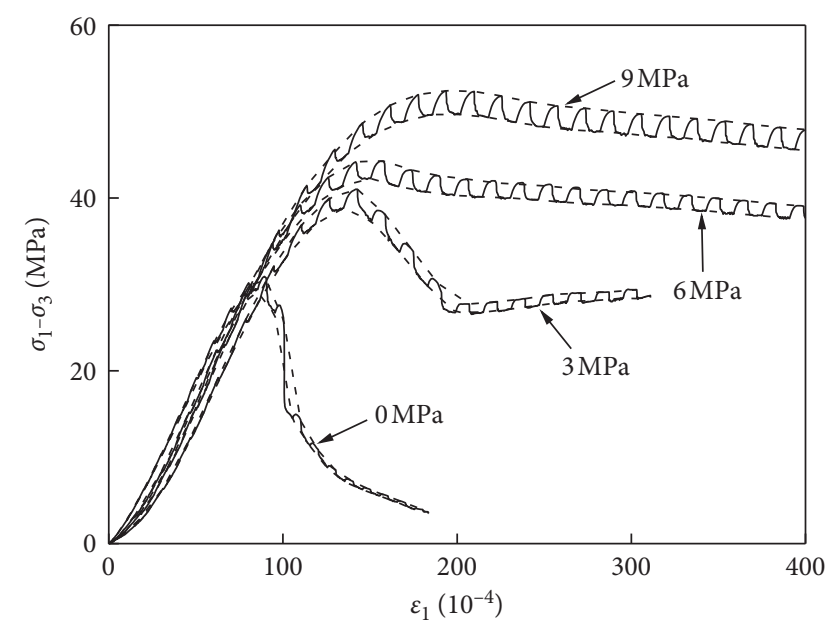

(b)

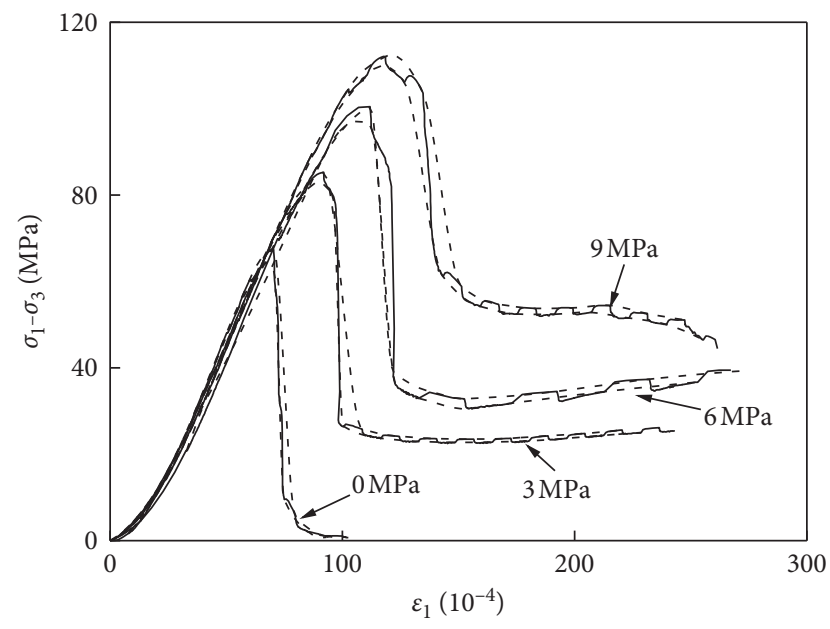

(d)

FIGURE 3: ASR stress-strain curves of air-dried rocks: (a) Tage tuff, (b) Ogino tuff, (c) Emochi andesite, (d) Jingkou sandstone.

value of $n$ can be easily calculated based on Equation (1) and ASR test results. To calculate $n_{i}$, the authors adopted four methods (a, b, c, and d) which were proposed by Hashiba et al. [16], as shown in Figure 6.

Figure 6 shows two stress-strain curves corresponding to strain rates of $C_{1}$ and $C_{2}$ obtained from the ASR test results. In the postfailure region, point $\mathrm{A}$ (the stress is $\sigma_{2}$ ) is located on the curve of $C_{2}$. Line a passes through $A$ and is perpendicular to the strain axis; line $\mathrm{b}$ joins the origin and point A; line $c$ passes through A with a slope equal to Young's modulus $(E)$; and line $\mathrm{d}$ passes through $\mathrm{A}$ with a slope equal to $E_{\mathrm{d}}$ obtained from the cyclic tests (given in the previous section). All the lines intersect with the curve of $C_{1}$, and the stresses at the intersection points are denoted by $\sigma_{1 \mathrm{a}}, \sigma_{1 \mathrm{~b}}, \sigma_{1 \mathrm{c}}$, and $\sigma_{1 \mathrm{~d}}$, respectively. The index of the loading-rate dependence is calculated using

$$
\frac{\sigma_{2}}{\sigma_{1 i}}=\left(\frac{C_{2}}{C_{1}}\right)^{1 /\left(n_{i}+1\right)} \quad(i=\mathrm{a}, \mathrm{b}, \mathrm{c}, \mathrm{d})
$$

Although method " $a$ " is the easiest to understand, a theoretical background is lacking. The theoretical background of method "b" is the variable compliance-type constitutive equation [17]. However, the nonlinear strain during the compression is not considered in this equation. Therefore, we calculated the index based on methods " $c$ " and "d" and discussed their relationship.

Table 3 lists the calculation results of $n_{\mathrm{c}}$ and $n_{\mathrm{d}}$ obtained under air-dried and wet conditions. For the four rocks, $n_{\mathrm{c}}$ is approximately equal to $n_{\mathrm{d}}$ under the same test condition. Figure 7 shows the relationship between $n_{\mathrm{c}}$ and $n_{\mathrm{d}}$ based on the values listed in Table $3 ; n_{\mathrm{c}}$ is proportional to $n_{\mathrm{d}}$, and the ratio is approximately 1 . Furthermore, the relationship between $n_{\mathrm{c}}$ and $n_{\mathrm{d}}$ was not affected by the rock type, moisture condition, or confining pressure. Therefore, the index $n_{\mathrm{c}}$, which is calculated using $E$, was used to assess the loading-rate dependence of the rocks in the postfailure region. Hence, the cyclic loading-unloading test was not conducted to reduce the effort and cost.

\subsection{Effects of Confining Pressure and Moisture Condition on} Index. Based on Equation (1) and ASR test results, the index $n$ of the peak strength is calculated. Table 4 lists the 


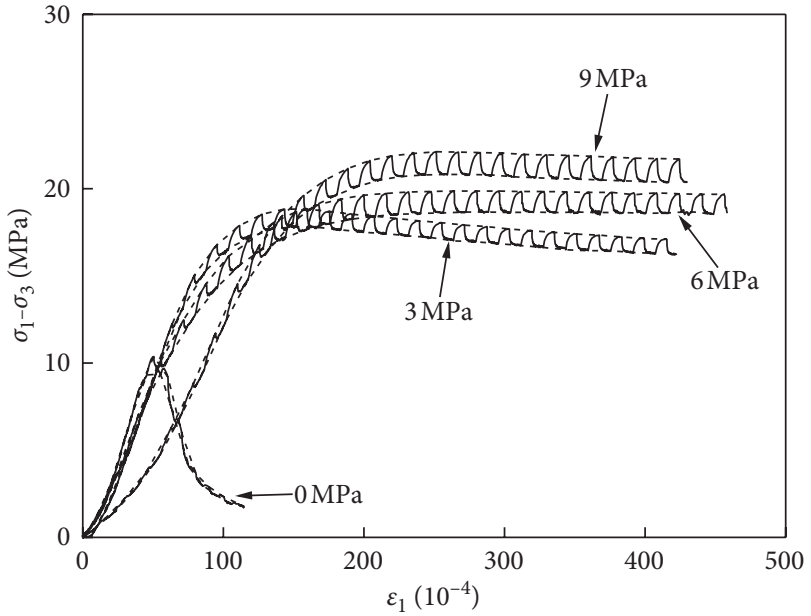

(a)

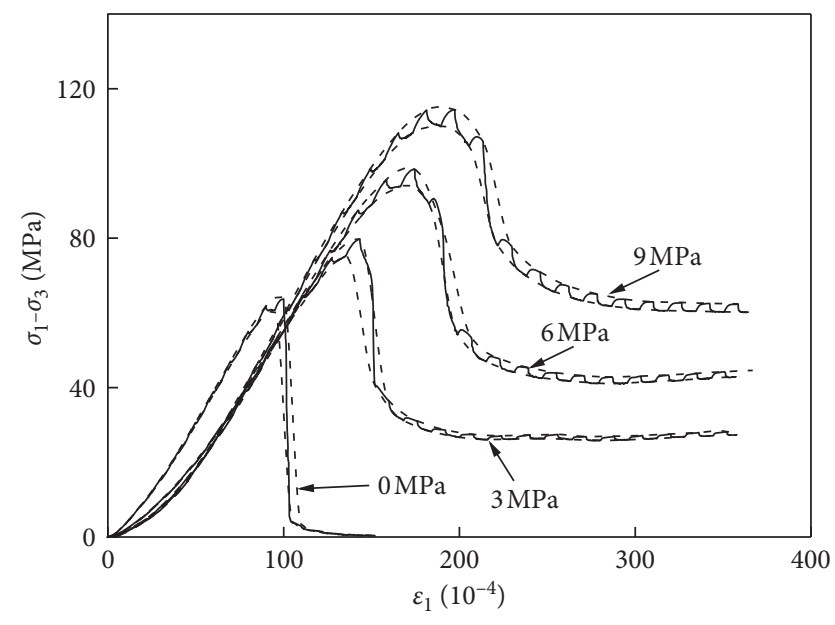

(c)

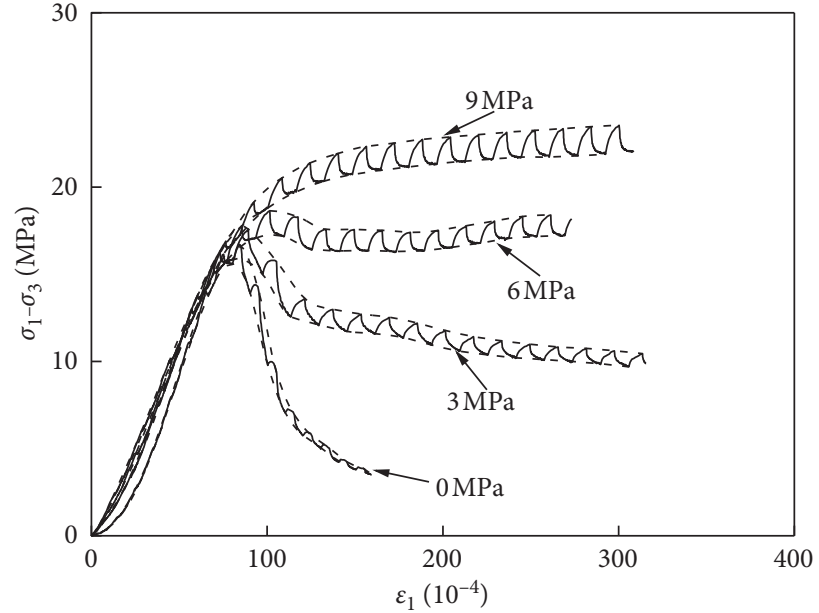

(b)

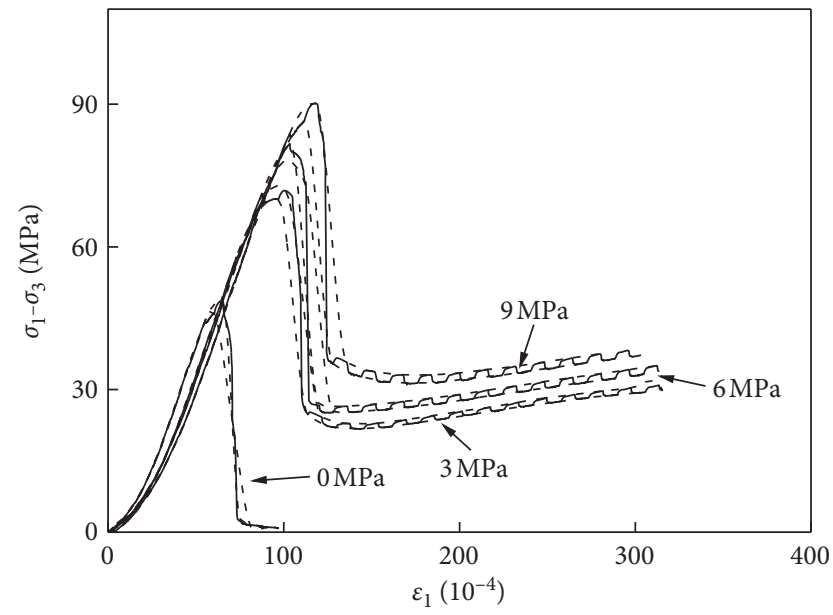

(d)

Figure 4: ASR stress-strain curves of wet rocks: (a) Tage tuff, (b) Ogino tuff, (c) Emochi andesite, (d) Jingkou sandstone.

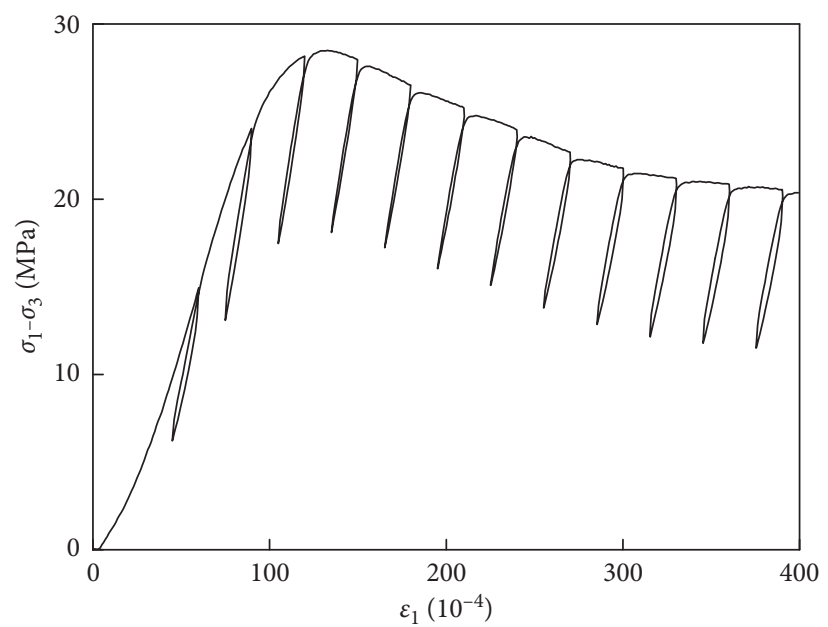

(a)

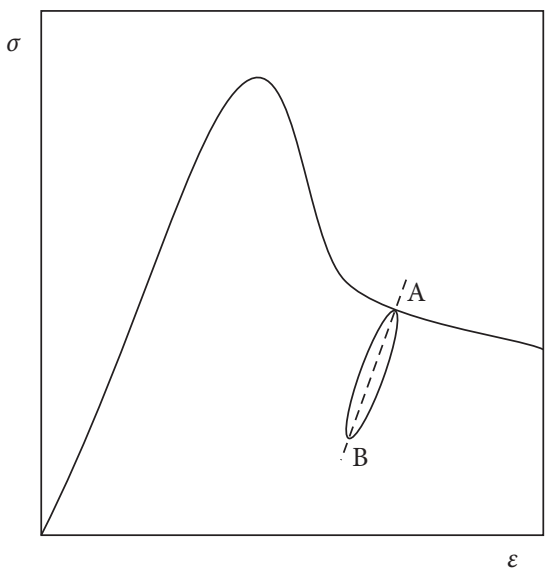

(b)

Figure 5: Calculation process of $E_{\mathrm{d}}$ (a) stress-strain curve, (b) calculation method. 
TABLE 2: Statistics of $E_{\mathrm{d}}$.

\begin{tabular}{lcccc}
\hline$\sigma_{3}(\mathrm{MPa})$ & $\begin{array}{c}\text { Tage } \\
\text { tuff }\end{array}$ & $\begin{array}{c}\text { Ogino } \\
\text { tuff }\end{array}$ & $\begin{array}{c}\text { Emochi } \\
\text { andesite }\end{array}$ & $\begin{array}{c}\text { Jingkou } \\
\text { sandstone }\end{array}$ \\
\hline Air-dried & & & $E_{\mathrm{d}}(\mathrm{GPa})$ & \\
3 & 5.57 & 7.19 & 7.65 & 8.21 \\
6 & 7.37 & 7.94 & 9.93 & 9.38 \\
9 & 7.23 & 8.54 & 10.22 & 10.22 \\
\hline Wet & & & $E_{\mathrm{d}}(\mathrm{GPa})$ & \\
3 & 4.66 & 5.65 & 9.30 & 5.99 \\
6 & 3.79 & 5.81 & 11.64 & 10.19 \\
9 & 4.12 & 6.23 & 12.01 & 13.07 \\
\hline
\end{tabular}

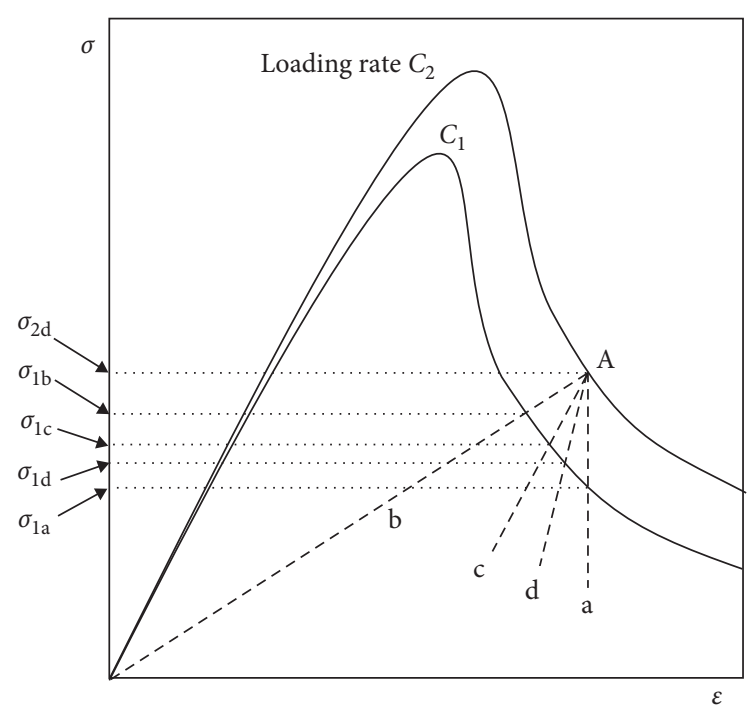

FIGURE 6: Sketch of stress corresponding points in the postfailure region [16]. Dotted lines correspond to constant strain (a), line passing through the origin (b), line with slope equal to Young's modulus (c), and unload modulus (d).

TABLE 3: Calculated results of $n_{\mathrm{c}}$ and $n_{\mathrm{d}}$.

\begin{tabular}{lccccc}
\hline \multirow{2}{*}{ Rock } & \multicolumn{2}{c}{$\sigma_{3}(\mathrm{MPa})$} & $\begin{array}{c}n_{\mathrm{c}} \\
n_{\mathrm{d}}\end{array}$ \\
& & Air-dried & Wet & Air-dried & Wet \\
\hline \multirow{3}{*}{ Tage tuff } & 3 & 68 & 45 & 66 & 43 \\
& 6 & 51 & 37 & 50 & 36 \\
& 9 & 50 & 38 & 50 & 39 \\
\hline \multirow{3}{*}{ Ogino tuff } & 3 & 65 & 33 & 64 & 33 \\
& 6 & 55 & 35 & 54 & 35 \\
& 9 & 45 & 32 & 45 & 32 \\
\hline \multirow{3}{*}{ Emochi andesite } & 3 & 74 & 58 & 74 & 57 \\
& 6 & 67 & 62 & 65 & 63 \\
& 9 & 66 & 61 & 64 & 61 \\
\hline \multirow{3}{*}{ Jingkou sandstone } & 3 & 45 & 50 & 45 & 49 \\
& 6 & 52 & 50 & 52 & 51 \\
& 9 & 66 & 50 & 60 & 51 \\
\hline
\end{tabular}

results. Water has a significant weakening effect on the peak strength and $n$ of all the rocks. For Tage tuff and Ogino tuff, the values of $n$ under the wet condition are lower than those under the air-dried condition, indicating that the loading-rate dependence of the peak strength under the wet condition is greater than that under the air-dried condition. Similarly, for

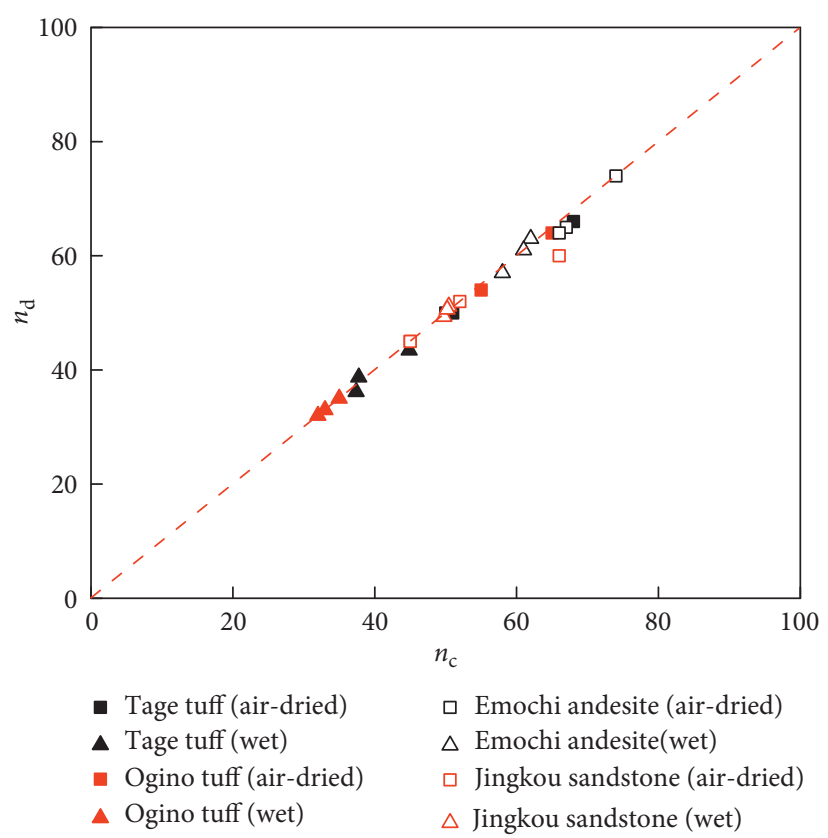

FIgURE 7: Relationship between $n_{\mathrm{c}}$ and $n_{\mathrm{d}}$.

TABLe 4: Calculated results of $n$.

\begin{tabular}{lccccc}
\hline \multirow{2}{*}{ Rock } & \multicolumn{2}{c}{$\sigma_{3}$} & \multicolumn{2}{c}{ Peak strength $(\mathrm{MPa})$} & \multicolumn{2}{c}{$n$} \\
& $(\mathrm{MPa})$ & Air-dried & Wet & Air-dried & Wet \\
\hline \multirow{4}{*}{ Tage tuff } & 0 & 22.26 & 10.81 & 42 & 30 \\
& 3 & 30.52 & 19.17 & 48 & 34 \\
& 6 & 35.42 & 20.25 & 48 & 36 \\
Ogino tuff & 9 & 40.39 & 20.67 & 50 & 40 \\
\hline \multirow{4}{*}{ Emochi andesite } & 0 & 27.35 & 15.52 & 36 & 24 \\
& 3 & 41.66 & 22.28 & 40 & 25 \\
& 6 & 46.69 & 23.69 & 43 & 29 \\
& 9 & 49.59 & 24.67 & 44 & 31 \\
\hline \multirow{3}{*}{ Jingkou } & 0 & 77.5 & 68.59 & 47 & 38 \\
sandstone & 9 & 115.20 & 91.83 & 53 & 44 \\
& 9 & 129.39 & 115.05 & 60 & 54 \\
\hline
\end{tabular}

Emochi andesite and Jingkou sandstone, the values of $n$ under the wet condition are lower than those under the air-dried condition. However, the difference in $n$ between the air-dried and wet conditions is lower than that for Tage tuff and Ogino tuff. This shows that the effect of water on the loading-rate dependence of the peak strengths of Tage tuff and Ogino tuff is greater than that on the loading-rate dependence of the peak strengths of Emochi andesite and Jingkou sandstone. The effects of water on $n_{\mathrm{c}}$ and $n_{\mathrm{d}}$ in the postfailure region, as listed in Table 3, are similar to that on $n$.

To investigate the effect of the confining pressure on the loading-rate dependence in the peak and postfailure regions, Figures 8 and 9 show the indices $n$ and $n_{\mathrm{d}}$ with respect to the 


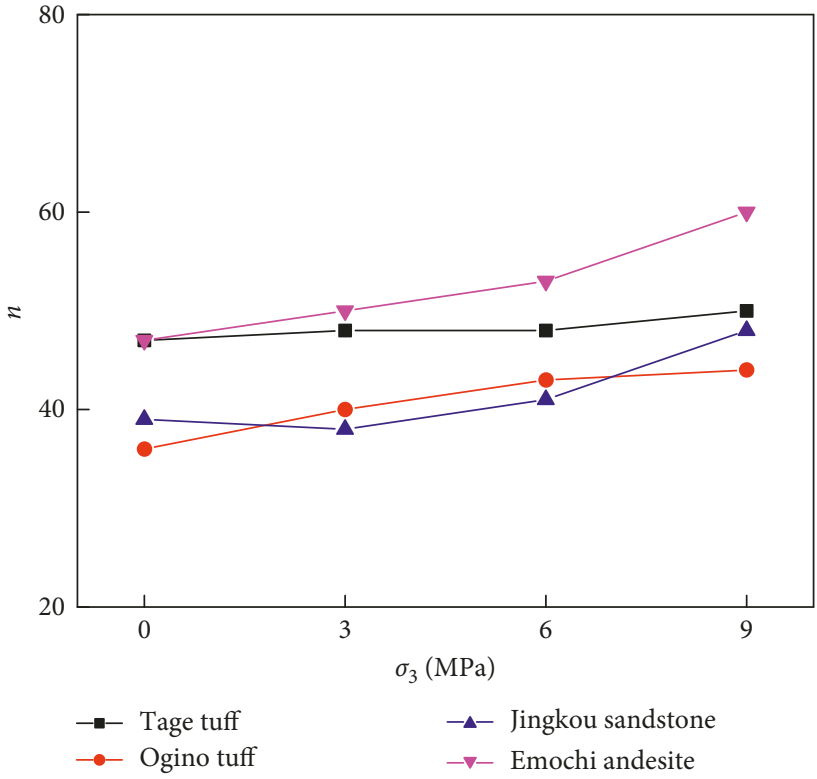

(a)

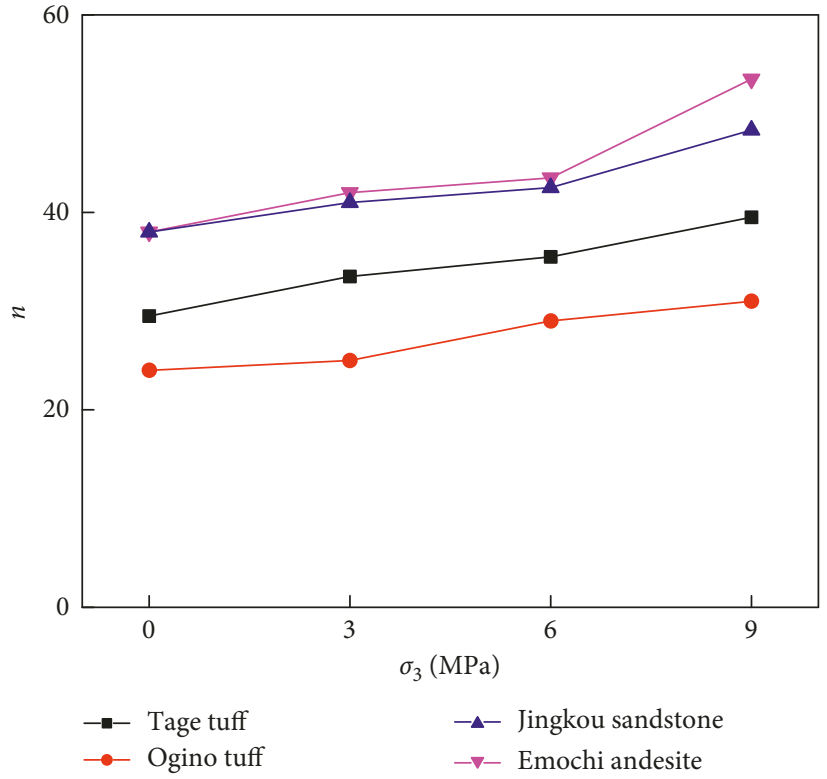

(b)

FIGURE 8: Loading-rate dependence index of peak strength with respect to confining pressure under (a) air-dried, (b) wet conditions.

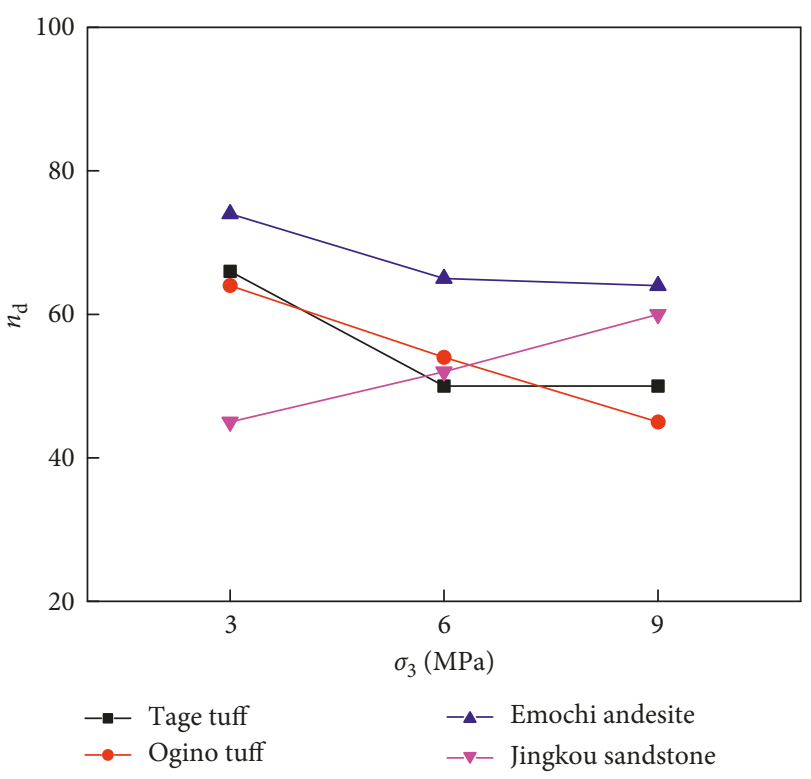

(a)

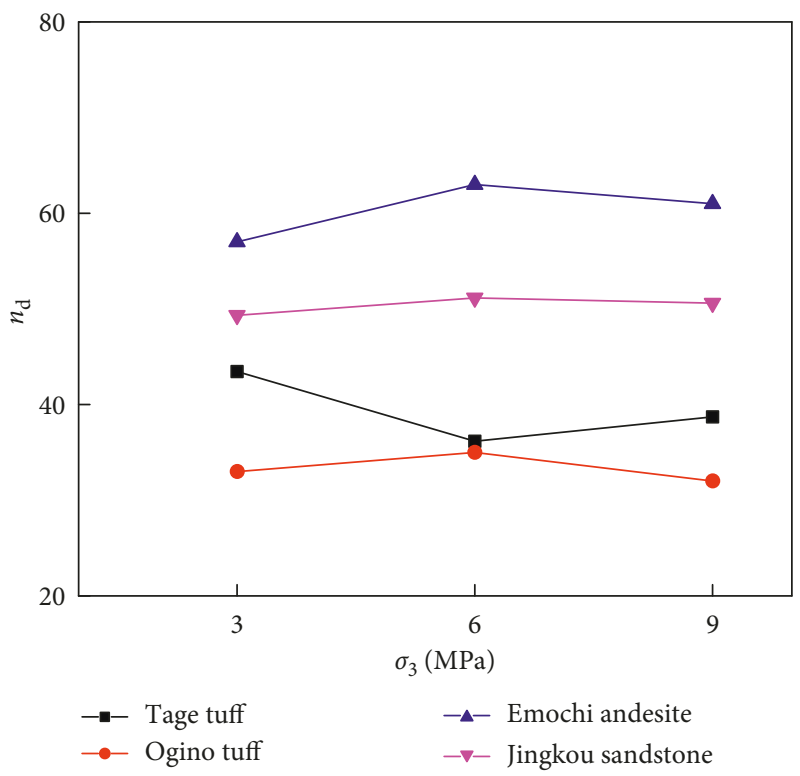

(b)

FIGURE 9: Loading-rate dependence index in the postfailure region with respect to the confining pressure under (a) air-dried, (b) wet conditions.

confining pressure, plotted based on the values listed in Tables 3 and 4, respectively. Figure 8 shows that the values of $n$ under the air-dried and wet conditions increase with the increase in the confining pressure, indicating that the increasing confining pressure reduces the loading-rate dependence of the peak strength. The effect of the confining pressure on the $n$ values of Tage tuff and Ogino tuff is relatively lower than that on the $n$ values of Emochi andesite and Jingkou sandstone.
Figure 9 shows that the value of $n_{\mathrm{d}}$ under the air-dried condition decreases with the increase in the confining pressure, except for the Jingkou sandstone sample. Under the wet condition, the value of $n_{\mathrm{d}}$ does not show a clear variation with respect to the confining pressure. From Table 3 , the value of $n_{\mathrm{d}}$ under the wet condition changes very slightly under the different confining pressures. Therefore, it can be considered that the confining pressure does not affect the loading-rate dependence in the postfailure region. Moreover, from 
Tables 3 and 4, it can be concluded that the effect of water on the loading-rate dependence of the rocks in the peak and postfailure regions is greater than that of the confining pressure.

3.5. Comparison between Peak and Postfailure Regions. Comparing Tables 3 and 4, the value of $n$ is lower than $n_{\mathrm{d}}$ in all cases, regardless of the condition (air-dried or wet), indicating that the loading-rate dependence in the peakfailure region is greater than that in the postfailure region. The ratio of $n$ under the wet condition to that under the airdried condition ( $n$ (wet) $/ n$ (air-dried)) was calculated for the range of confining pressures employed in this study. The ratios $(n)$ for the Tage tuff (under different confining pressures), Ogino tuff, Emochi andesite, and Jingkou sandstone are in the ranges of $71-80 \%, 63-70 \%, 80-89 \%$, and $97-100 \%$, respectively. The results of $n_{\mathrm{d}}\left(n_{\mathrm{d}}\right.$ (wet) $/ n_{\mathrm{d}}$ (airdried)) for the Tage tuff, Ogino tuff, Emochi andesite, and Jingkou sandstone are in the ranges of $66-76 \%$ (under different confining pressures), 52-71\%, 77-95\%, and 84$100 \%$, respectively. Therefore, water has a greater effect on the loading-rate dependence in the postfailure region.

\section{Discussion}

4.1. Stress Increment. To study the loading-rate dependence of the rocks in the peak and postfailure regions, it is necessary to obtain the stress increment values with ten-fold increase in the strain rate. The equations to calculate the same are as follows:

$$
\begin{gathered}
\Delta \sigma=\sigma_{2 \mathrm{f}}-\sigma_{1 \mathrm{f}}, \\
\Delta \sigma_{\mathrm{d}}=\sigma_{2}-\sigma_{1 \mathrm{~d}} .
\end{gathered}
$$

The following equations [3] are obtained by substituting Equations (3) and (4) in Equations (1) and (2), respectively:

$$
\begin{gathered}
\Delta \sigma=\sigma_{1 \mathrm{f}}\left(10^{1 /(n+1)}-1\right), \\
\Delta \sigma_{\mathrm{d}}=\sigma_{1 \mathrm{~d}}\left(10^{1 /\left(n_{\mathrm{d}}+1\right)}-1\right),
\end{gathered}
$$

where $\triangle \sigma$ and $\triangle \sigma_{\mathrm{d}}$ are the increments with ten-fold increase in the strain rate in the peak and postfailure regions, respectively. From Equations (5) and (6), $\triangle \sigma$ and $\triangle \sigma_{\mathrm{d}}$ are found to be proportional to $\sigma_{1 \mathrm{f}}$ (deviator stress) and $\sigma_{1 \mathrm{~d}}$ (deviator stress), respectively.

Figure 10 shows the changes in $\triangle \sigma$ for the four rocks under the air-dried and wet conditions. The results show that $\triangle \sigma$ increases with the increase in $\sigma_{1 \mathrm{f}}$ (deviator stress) under the air-dried and wet conditions. The values of $\triangle \sigma$ for the Tage tuff and Ogino tuff samples are lower; however, the increment in $\triangle \sigma$ is greater than those for Emochi andesite and Jingkou sandstone, based on the comparison of the slopes of the fitting lines. The data pertaining to the sandstone samples under the wet condition are relatively scattered.

Figure 11 shows the changes in $\triangle \sigma_{\mathrm{d}}$ for the four rocks under the air-dried and wet conditions. Similar to $\triangle \sigma$, $\triangle \sigma_{\mathrm{d}}$ increases with the increase in $\sigma_{1 \mathrm{~d}}$ (deviator stress) under the air-dried and wet conditions.

Overall, both $\triangle \sigma$ and $\triangle \sigma_{\mathrm{d}}$ have a good linear relationship with $\sigma_{1 \mathrm{f}}$ and $\sigma_{1 \mathrm{~d}}$, respectively, under both airdried and wet conditions. As mentioned in the previous section, it is difficult to quantitatively study the loading-rate dependence of rocks in the postfailure region when the confining pressure is zero. Based on the results obtained in this section, $\triangle \sigma_{\mathrm{d}}$ can be estimated using Equations (4) and (6). The index $n_{\mathrm{d}}$ corresponding to a confining pressure of $0 \mathrm{MPa}$ can be calculated using Equation (2).

4.2. Verification of Test Results. In the previous section, we found that $n_{\mathrm{c}}$ calculated using $E$ was approximately equal to $n_{\mathrm{d}}$ calculated using $E_{\mathrm{d}}$. Therefore, $n_{\mathrm{d}}$ can be replaced by $n_{\mathrm{c}}$ to assess the loading-rate dependence of the rocks in the postfailure region. However, only few quantitative results on the loading-rate dependence in the postfailure region are available in literature. Therefore, we need to verify the results of the ASR tests. Hashiba and Fukui [14] demonstrated that the various time-dependent behaviors, such as the loadingrate dependence, creep, and stress relaxation, are closely related. Hence, stress relaxation tests were conducted in the postfailure region, and a nonlinear constitutive equation, the parameters of which are obtained from the ASR tests, was employed to determine the stress relaxation. Based on the comparison of the experimental and calculated results, the reliability of the ASR test results was verified.

The stress relaxation tests were conducted, and the airdried Tage tuff was taken as the example under confining pressures of 3,6, and $9 \mathrm{MPa}$. In addition, stress relaxation tests on the air-dried Ogino tuff, Emochi andesite, and Jingkou sandstone samples were conducted under a confining pressure of $6 \mathrm{MPa}$. The relaxation time was $10^{5} / \mathrm{s}$. The strain was controlled with a strain rate of $10^{-4} / \mathrm{s}$ for loading up to the start point of the stress relaxation. The start points are located in the stable region of the stress-strain curves in the postfailure region. Table 5 lists the strain and stress values at the start points.

The Nonlinear Maxwell model proposed by Okubo and Fukui [18] was used to simulate the stress relaxation of rocks in postfailure region. For conventional Maxwell model, $\sigma$ is proportional to the rate of dashpot strain $\left(d \varepsilon_{2} / d t\right)$. For the Nonlinear Maxwell model in Figure 12, $\sigma$ follows the powerlaw like a non-Newtonian fluid. Accordingly, the constitutive equations can be written as follows:

$$
\begin{aligned}
& \varepsilon=\varepsilon_{1}+\varepsilon_{2}, \\
& \sigma=E \varepsilon_{1}, \\
& \sigma=\eta\left(\frac{d \varepsilon_{2}}{d t}\right)^{(1 / n)},
\end{aligned}
$$

where $\varepsilon_{1}$ and $\varepsilon_{2}$ denote the strain values of the spring and dashpot, respectively, $\eta$ is the viscosity coefficient of the dashpot, and $\sigma$ is the stress at the start point of stress relaxation. $n$ was obtained from the ASR test results. $E$ and $E_{\mathrm{d}}$ 


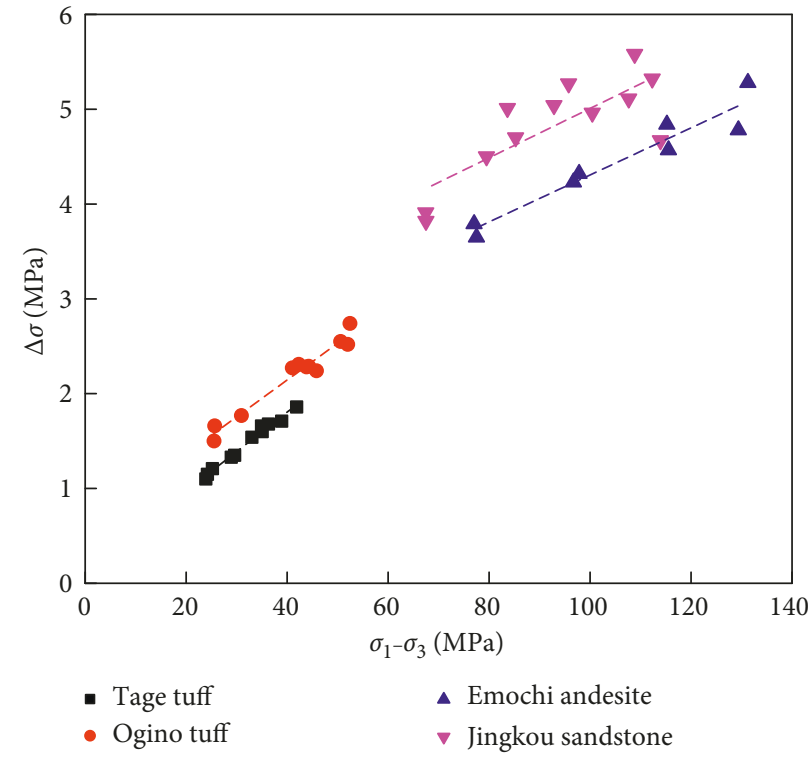

(a)

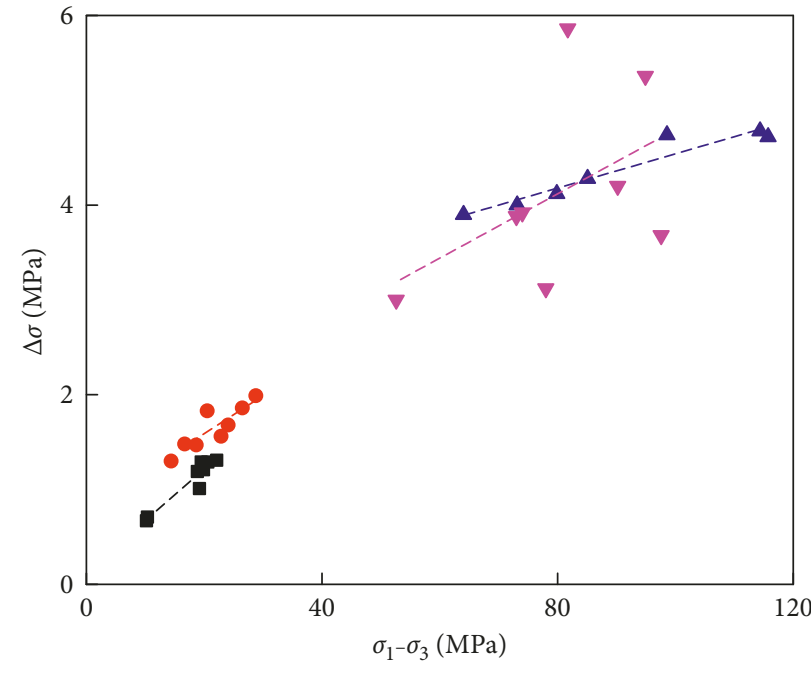

- Tage tuff

- Ogino tuff
- Emochi andesite

$\checkmark$ Jingkou sandstone

(b)

FIGURE 10: $\triangle \sigma$ versus peak strength under (a) air-dried, (b) wet conditions.

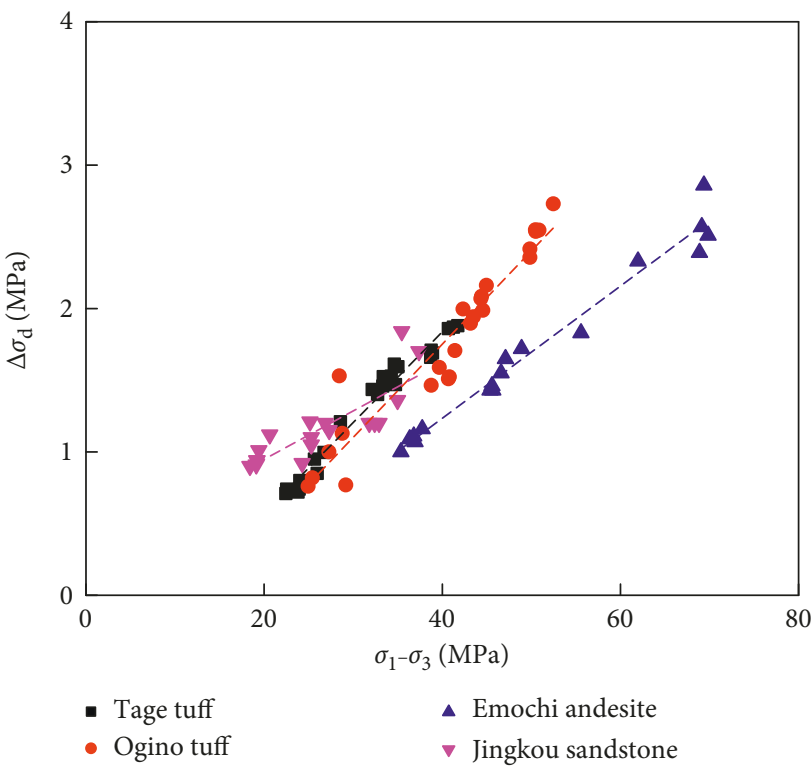

(a)

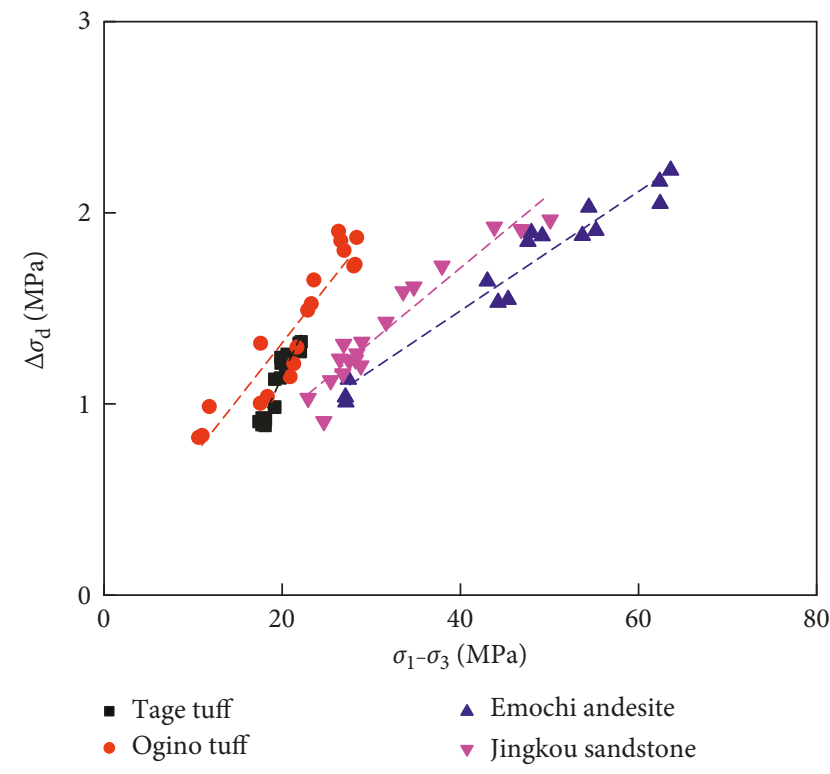

(b)

FIGURE 11: $\triangle \sigma_{\mathrm{d}}$ vs stress in the postfailure region under (a) air-dried, (b) wet conditions.

TABLE 5: Values of parameters.

\begin{tabular}{|c|c|c|c|c|c|c|c|}
\hline \multirow{2}{*}{ Rock } & \multirow{2}{*}{$\sigma_{3}(\mathrm{MPa})$} & \multicolumn{2}{|c|}{ Start points } & \multirow{2}{*}{$E(\mathrm{MPa})$} & \multirow{2}{*}{$E_{\mathrm{d}}(\mathrm{MPa})$} & \multirow{2}{*}{$n$} & \multirow[b]{2}{*}{$\eta$} \\
\hline & & Strain $\left(10^{-4}\right)$ & Stress $(\mathrm{MPa})$ & & & & \\
\hline \multirow{3}{*}{ Tage tuff } & 3 & 300 & 22.09 & 4030 & 5570 & 48 & 26.76 \\
\hline & 6 & 300 & 32.15 & 4180 & 7370 & 48 & 39.01 \\
\hline & 9 & 300 & 22.09 & 4630 & 7230 & 50 & 44.84 \\
\hline Ogino tuff & 6 & 300 & 32.11 & 4540 & 7940 & 43 & 43.50 \\
\hline Emochi andesite & 6 & 300 & 67.55 & 9070 & 9930 & 53 & 80.49 \\
\hline Jingkou sandstone & 6 & 200 & 27.56 & 11210 & 9380 & 41 & 34.43 \\
\hline
\end{tabular}




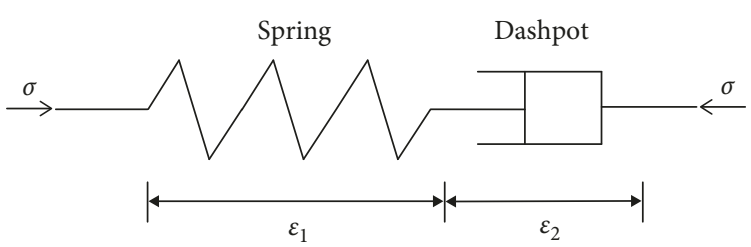

FIgURE 12: Schematic diagram the of Maxwell model.

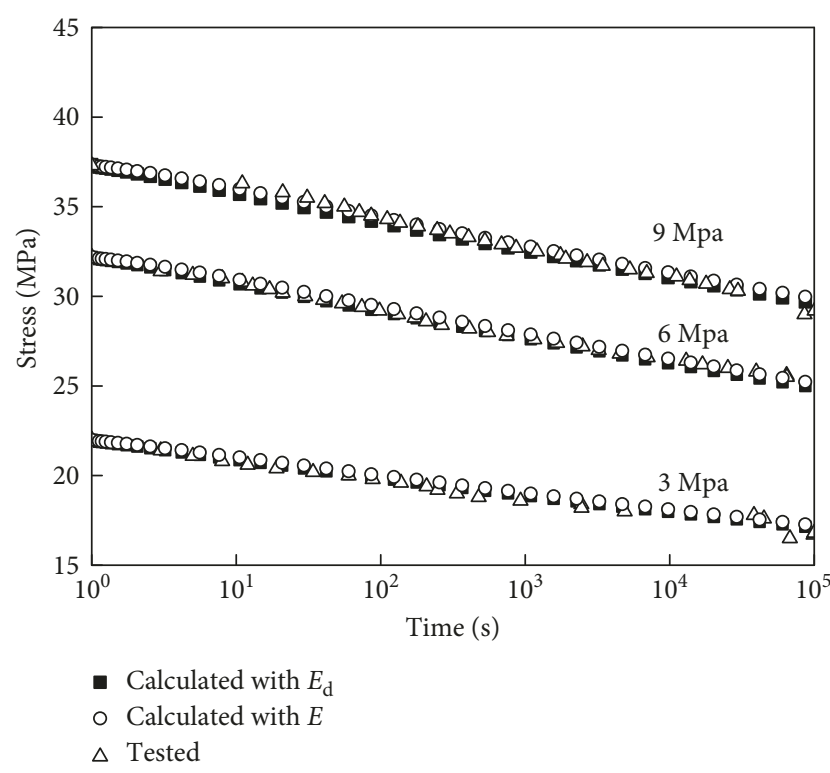

(a)

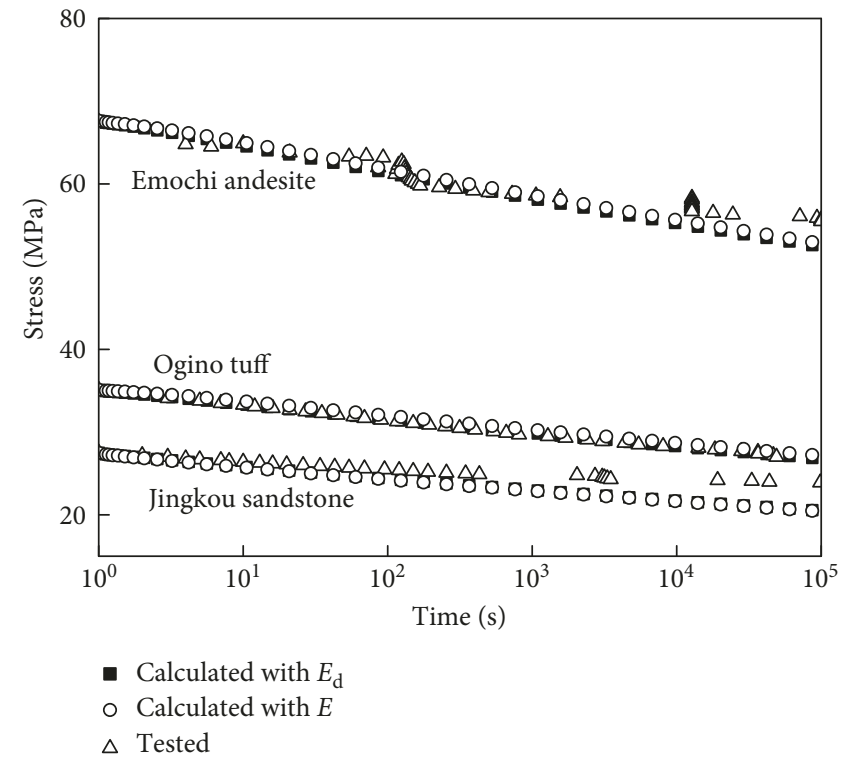

(b)

Figure 13: Comparison of experimental and calculated results of stress relaxation in the postfailure region for (a) Tage tuff, (b) other rocks.

were used for the calculation in Equation (8). Table 5 lists the values of the parameters.

Figure 13 shows the comparison of the experimental and calculated results of stress relaxation for the four rocks under the different confining pressures on a semilogarithmic chart. The calculated and experimental results are in good agreement. There is no obvious difference between the calculations with $E$ and $E_{\mathrm{d}}$. This demonstrates the reliability of the parameters obtained from the ASR test results.

4.3. Research Limitations and Suggestions. Although we investigated the loading-rate dependence of various rocks in the peak and postfailure regions under different confining pressure and moisture conditions, there are some limitations in this study. Therefore, following are the suggestions given to improve this study and the direction for future research:

(i) The mechanism of the effect of confining pressure or moisture condition on $n$ and $n_{\mathrm{d}}$ values for various rocks should be studied. For example, the physicochemical effects of water on the loading-rate dependence of the rocks in the peak and postfailure regions can be investigated.

(ii) The evolution of the stress-strain curve is related to the evolutionary morphology and propagation path of cracks [19]. Therefore, it is important to investigate the relationship between crack propagation and fracture mechanism and the loading-rate dependence of rocks.

(iii) The ASR test results show that brittle rocks (e.g., Jingkou sandstone) fail abruptly after the peak strength, and the stress decreases almost instantaneously. This failure process cannot be controlled using the conventional strain control mode. Therefore, special control methods need to be considered to accurately obtain the stress-strain curve after the peak strength, such as the linear combination of stress and strain $[20,21]$ or constant lateral-strain rate method [22]. Based on these methods, the loading-rate dependence of brittle rocks in the postfailure region can be more accurately investigated.

\section{Conclusion}

In this study, with Tage tuff, Ogino tuff, Emochi andesite, and Jingkou sandstone as the research subjects, ASR and cyclic loading-unloading tests were conducted to investigate the loading-rate dependence of these rocks in the peak and postfailure regions. An index of the loading-rate 
dependence in the postfailure region was proposed. The effects of confining pressure and moisture condition on the indices $n$ and $n_{\mathrm{d}}$ were discussed. Finally, stress relaxation tests were conducted in the postfailure region and later compared with the results obtained using the nonlinear Maxwell model to verify the reliability of the ASR test results. Following are the main conclusions drawn from this study:

(i) The stress fluctuated with the change in the strain rate, which is closely related to the loading-rate dependence. Both the air-dried and wet rocks exhibit loading-rate dependence in the pre, peak, and postfailure regions.

(ii) A method to calculate the loading-rate dependence index in the postfailure region was proposed. The value of $n_{c}$ calculated using $E$ is largely equal to the value of $n_{\mathrm{d}}$ calculated using $E_{\mathrm{d}}$. In the future, $n_{\mathrm{c}}$ can be used to assess the loadingrate dependence in the postfailure region. This would put an end to the time-consuming and costly cyclic tests.

(iii) For Tage tuff and Ogino tuff, the loading-rate dependence in the peak and postfailure regions under the wet condition was greater than that under the air-dried condition. The effects of water on Emochi andesite and Jingkou sandstone were minor. The effect of water on the loading-rate dependence of the rocks was greater than that of the confining pressure. The loading-rate dependence in the peakfailure region was greater than that in the postfailure region, regardless of the condition employed (air-dried or wet).

(iv) The loading-rate dependence of the peak strength decreased with the increase in the confining pressure. The effects of the confining pressure on the loading-rate dependence of the peak strengths of Tage tuff and Ogino tuff were relatively lower than those on the loading-rate dependence of the peak strengths of Emochi andesite and Jingkou sandstone. The increase in the confining pressure increased the loading-rate dependence of Tage tuff, Ogino tuff, and Emochi andesite in the postfailure region under the air-dried condition. The loadingrate dependence of the wet rocks in the postfailure region did not exhibit any significant variation with the increase in the confining pressure.

\section{Data Availability}

The data of alternative strain rate test, cycle loadingunloading test under different confining pressure, and water content used to support the findings of this study are included within the article.

\section{Conflicts of Interest}

The authors declare no conflicts of interest.

\section{Acknowledgments}

The authors would like to thank the National Natural Science Foundation of China (51434003), Basic and Frontier Research Projects of Chongqing (cstc2016jcyjA0117), and Project of Science and Technology for Chongqing Education Commission (no. KJ1711271) for the financial support.

\section{References}

[1] W. Yang, R. Gamage, C. Huang, G. Luo, J. Guo, and S. Wang, "Loading history effect on creep deformation of rock," Energies, vol. 11, no. 6, p. 1462, 2018.

[2] L. Ma and J. J. K. Daemen, "Strain rate dependent strength and stress-strain characteristics of a welded tuff," Bulletin of Engineering Geology and the Environment, vol. 65, no. 3, pp. 221-230, 2006.

[3] K. Hashiba and K. Fukui, "Index of loading-rate dependency of rock strength," Rock Mechanics and Rock Engineering, vol. 48, no. 2, pp. 859-865, 2015.

[4] F. Gao and H. Kang, "Experimental study on the residual strength of coal under low confinement," Rock Mechanics and Rock Engineering, vol. 50, no. 2, pp. 285-296, 2017.

[5] F. Rummel and C. Fairhurst, "Determination of the postfailure behavior of brittle rock using a servo-controlled testing machine," Rock Mechanics, vol. 2, no. 4, pp. 189-204, 1970.

[6] Z. T. Bieniawski, "Time-dependent behavior of fractured rock," Rock Mechanics, vol. 2, no. 3, pp. 123-137, 1970.

[7] S. Peng and E. R. Podnieks, "Relaxation and the behavior of failed rock," International Journal of Rock Mechanics and Mining Sciences \& Geomechanics Abstracts, vol. 9, no. 6, pp. 699-700, 1972.

[8] S. S. Peng, "Time-dependent aspects of rock behavior as measured by a servo-controlled hydraulic testing machine," International Journal of Rock Mechanics and Mining Sciences \& Geomechanics Abstracts, vol. 10, no. 3, pp. 235-246, 1973.

[9] K. Hashiba, S. Okubo, and K. Fukui, "A new testing method for investigating the loading rate dependency of peak and residual rock strength," International Journal of Rock Mechanics and Mining Sciences, vol. 43, no. 6, pp. 894-904, 2006.

[10] K. Shin, S. Okubo, K. Fukui, and K. Hashiba, "Variation in strength and creep life of six Japanese rocks," International Journal of Rock Mechanics and Mining Sciences, vol. 42, no. 2, pp. 251-260, 2005.

[11] S. Okubo, K. Hashiba, and K. Fukui, "Loading rate dependency of the strengths of some Japanese rocks," International Journal of Rock Mechanics and Mining Sciences, vol. 58, no. 1, pp. 180-185, 2013.

[12] S. Okubo, Y. Nishimatsu, and C. He, "Loading-rate dependence of class II rock behavior in uniaxial and triaxial compression tests-an application of a proposed new control method," International Journal of Rock Mechanics and Mining Sciences \& Geomechanics Abstracts, vol. 27, no. 6, pp. 559562, 1990.

[13] S. Okubo, Y. Nishimatsu, and K. Fukui, "Complete creep curves under uniaxial compression," International Journal of Rock Mechanics and Mining Sciences \& Geomechanics Abstracts, vol. 28, no. 1, pp. 77-82, 1991.

[14] K. Hashiba and K. Fukui, "Time-dependent behaviors of granite: loading-rate dependence, creep, and relaxation," Rock Mechanics and Rock Engineering, vol. 49, no. 7, pp. 25692580, 2016.

[15] K. Hashiba and K. Fukui, "Index of time-dependency for rock and its application for the assessment of the long-term 
stability of underground structures," in Proceedings of EurockISRM International Symposium, Wroclaw, Poland, 2013.

[16] K. Hashiba, M. Lei, S. Okubo, and K. Fukui, "Loading-rate dependency of stress-strain curve for rocks in the post-failure region," Journal of MMIJ, vol. 125, no. 3, pp. 98-105, 2009.

[17] S. Okubo, C. R. He, and Y. Nishimatsu, "Time dependent behavior in uniaxial compression-rheological behavior of rock in post-failure region (1st report)," Journal of the Mining Institute of Japan, vol. 103, no. 1189, pp. 177-181, 1987.

[18] S. Okubo and K. Fukui, "An analytical investigation of a variable-compliance-type constitutive equation," Rock Mechanics and Rock Engineering, vol. 39, no. 3, pp. 233-253, 2006.

[19] W. R. Wawersik and W. F. Brace, "Post-failure behavior of a granite and diabase," Rock Mechanics, vol. 3, no. 2, pp. 61-85, 1971.

[20] P. Z. Pan, X. T. Feng, and J. A. Hudson, "Numerical simulations of class I and class II uniaxial compression curves using an elasto-plastic cellular automaton and a linear combination of stress and strain as the control method," International Journal of Rock Mechanics and Mining Sciences, vol. 43, no. 7, pp. 1109-1117, 2006.

[21] S. Okubo and Y. Nishimatsu, "Uniaxial compression testing using a linear combination of stress and strain as the control variable," International Journal of Rock Mechanics and Mining Sciences \& Geomechanics Abstracts, vol. 22, no. 5, pp. 323330, 1985.

[22] H. Munoz, A. Taheri, and E. K. Chanda, "Pre-peak and postpeak rock strain characteristics during uniaxial compression by 3D digital image correlation," Rock Mechanics and Rock Engineering, vol. 49, no. 7, pp. 2541-2554, 2016. 


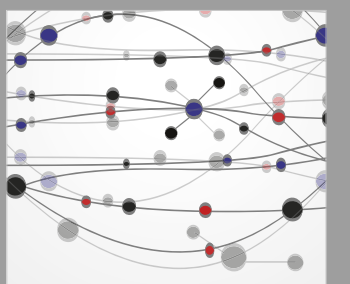

The Scientific World Journal
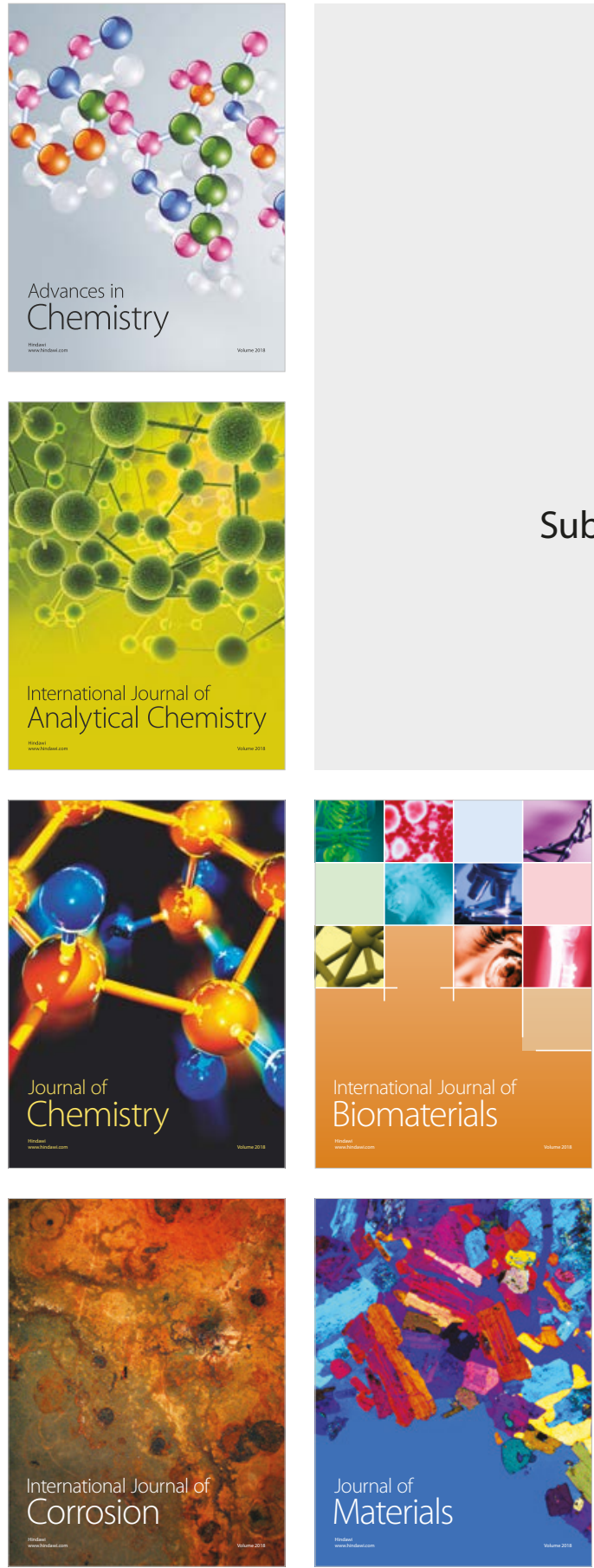

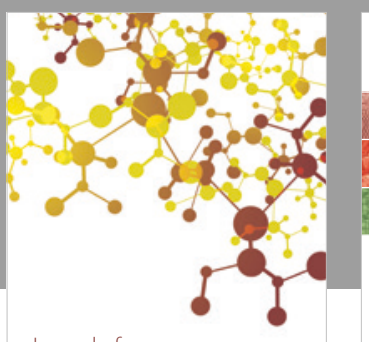

Journal of

Applied Chemistry
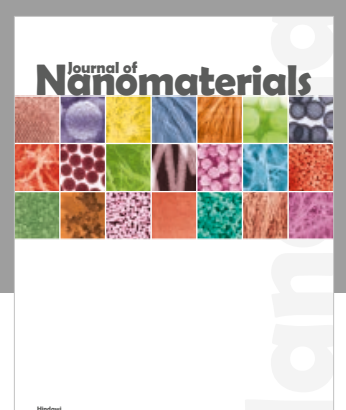

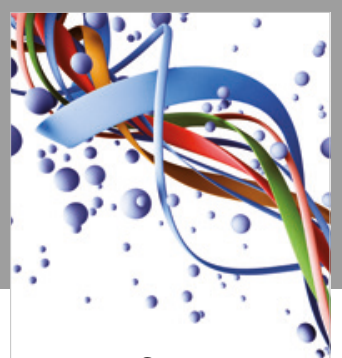

Scientifica

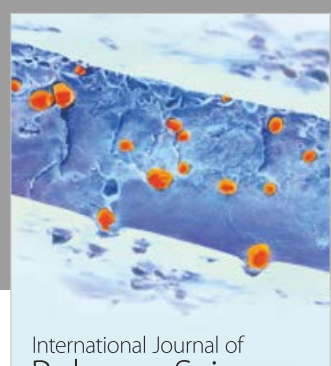

Polymer Science

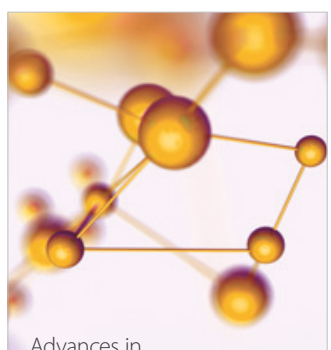

Physical Chemistry
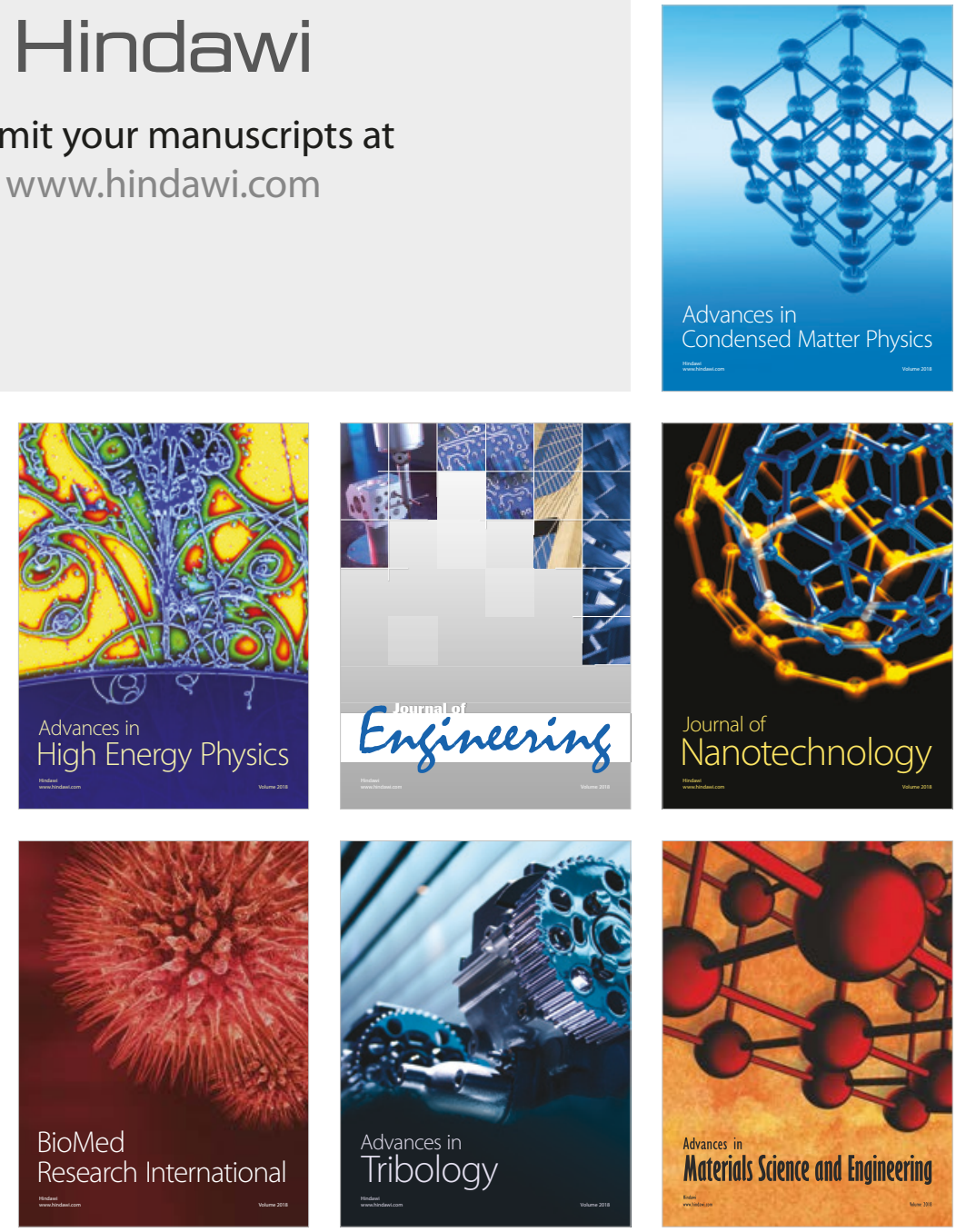